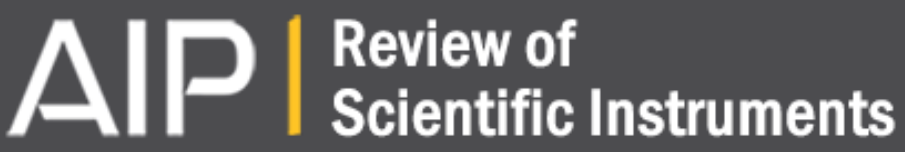

\section{Invited Review Article: Advanced light microscopy for biological space research}

Winnok H. De Vos, Didier Beghuin, Christian J. Schwarz, David B. Jones, Jack J. W. A. van Loon, Juergen Bereiter-Hahn, and Ernst H. K. Stelzer

Citation: Review of Scientific Instruments 85, 101101 (2014); doi: 10.1063/1.4898123

View online: http://dx.doi.org/10.1063/1.4898123

View Table of Contents: http://scitation.aip.org/content/aip/journal/rsi/85/10?ver=pdfcov

Published by the AIP Publishing

\section{Articles you may be interested in}

Study of radiation effects on the cell structure and evaluation of the dose delivered by $\mathrm{x}$-ray and $\alpha$-particles microscopy

Appl. Phys. Lett. 101, 263102 (2012); 10.1063/1.4773181

Invited Review Article: Combining scanning probe microscopy with optical spectroscopy for applications in biology and materials science

Rev. Sci. Instrum. 83, 061101 (2012); 10.1063/1.4720102

Deactivation of A549 cancer cells in vitro by a dielectric barrier discharge plasma needle J. Appl. Phys. 109, 053305 (2011); 10.1063/1.3553873

Advanced research equipment for fast ultraweak luminescence analysis

Rev. Sci. Instrum. 74, 4485 (2003); 10.1063/1.1611997

Autonomous biological system-an unique method of conducting long duration space flight experiments for pharmaceutical and gravitational biology research

AIP Conf. Proc. 420, 616 (1998); 10.1063/1.54854

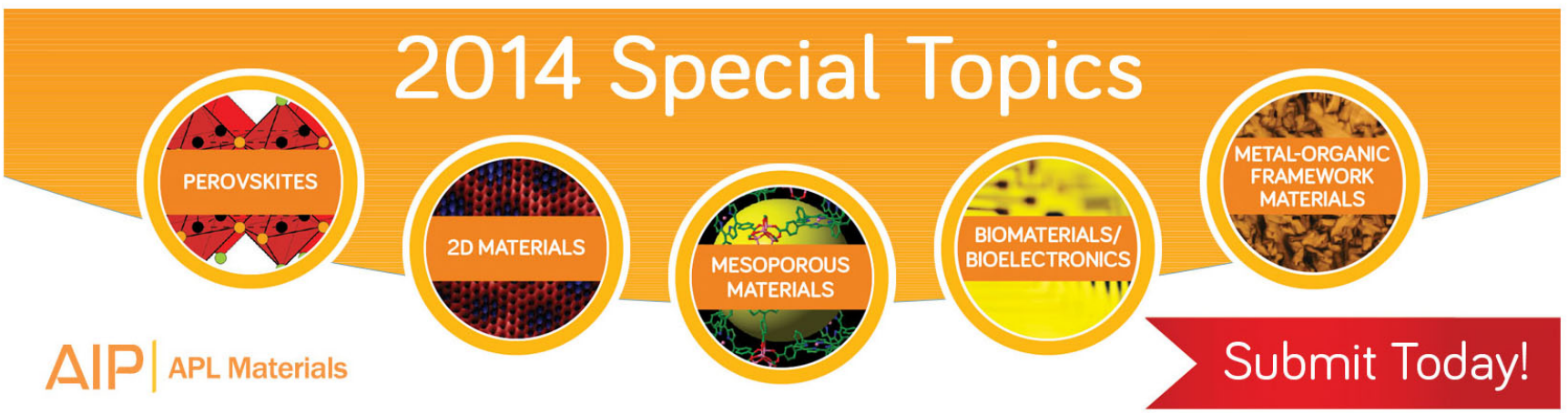




\title{
Invited Review Article: Advanced light microscopy for biological space research
}

\author{
Winnok H. De Vos, ${ }^{1,2, a)}$ Didier Beghuin, ${ }^{3}$ Christian J. Schwarz, ${ }^{4}$ David B. Jones, ${ }^{5}$ \\ Jack J. W. A. van Loon, ${ }^{6}$ Juergen Bereiter-Hahn, ${ }^{7}$ and Ernst H. K. Stelzer ${ }^{7}$ \\ ${ }^{1}$ Laboratory of Cell Biology and Histology, Department of Veterinary Sciences, University of Antwerp, \\ Antwerp, Belgium \\ ${ }^{2}$ Cell Systems and Imaging Research Group, Department of Molecular Biotechnology, Ghent University, \\ Ghent, Belgium \\ ${ }^{3}$ Lambda-X, Nivelles, Belgium \\ ${ }^{4}$ European Space Agency (ESA), ESTEC, TEC-MMG, Noordwijk, The Netherlands \\ ${ }^{5}$ Institute for Experimental Orthopaedics and Biomechanics, Philipps University, Marburg, Germany \\ ${ }^{6}$ Department of Oral and Maxillofacial Surgery/Oral Pathology, VU University Medical Center and \\ Department of Oral Cell Biology, Academic Centre for Dentistry Amsterdam, Amsterdam, The Netherlands \\ ${ }^{7}$ Physical Biology, BMLS (FB15, IZN), Goethe University, Frankfurt am Main, Germany
}

(Received 21 May 2014; accepted 1 October 2014; published online 27 October 2014)

As commercial space flights have become feasible and long-term extraterrestrial missions are planned, it is imperative that the impact of space travel and the space environment on human physiology be thoroughly characterized. Scrutinizing the effects of potentially detrimental factors such as ionizing radiation and microgravity at the cellular and tissue level demands adequate visualization technology. Advanced light microscopy (ALM) is the leading tool for non-destructive structural and functional investigation of static as well as dynamic biological systems. In recent years, technological developments and advances in photochemistry and genetic engineering have boosted all aspects of resolution, readout and throughput, rendering ALM ideally suited for biological space research. While various microscopy-based studies have addressed cellular response to space-related environmental stressors, biological endpoints have typically been determined only after the mission, leaving an experimental gap that is prone to bias results. An on-board, real-time microscopical monitoring device can bridge this gap. Breadboards and even fully operational microscope setups have been conceived, but they need to be rendered more compact and versatile. Most importantly, they must allow addressing the impact of gravity, or the lack thereof, on physiologically relevant biological systems in space and in ground-based simulations. In order to delineate the essential functionalities for such a system, we have reviewed the pending questions in space science, the relevant biological model systems, and the state-of-the art in ALM. Based on a rigorous trade-off, in which we recognize the relevance of multi-cellular systems and the cellular microenvironment, we propose a compact, but flexible concept for space-related cell biological research that is based on light sheet microscopy. (C) 2014 AIP Publishing LLC. [http://dx.doi.org/10.1063/1.4898123]

\section{ABBREVIATIONS}

ALM

AMME

AMERE

BIFC

CFM

DSLM

FLAP

FLIP

FLIM

FRAP

FRET
Advanced light microscopy

Advanced microscopy methods

Autonomous microscope for the evaluation of radiation effects

Bimolecular fluorescence complementation

Confocal fluorescence microscopy

Digitally scanned light sheet microscopy

Fluorescence localization after photobleaching

Fluorescence loss in photobleaching

Fluorescence lifetime microscopy

Fluorescence recovery after photobleaching

Förster resonance energy transfer
HZE

ISS

LDC

LMM

LSFM

MELISSA

MPM

NA

NIZEMI

PALM

PSF

ROI

RPM

SIM

SLM

SPIM
Ionized particles of high charge $(\mathrm{Z})$ and high energy

International Space Station

Large diameter centrifuge

Light microscopy module

Light sheet fluorescence microscopy

Micro Ecological Life Support System Alternative

Multiphoton microscopy

Numerical aperture

Niedergeschwindigkeits zentrifugen mikroskop

Photo-activation localization microscopy

Point spread function

Region of interest

Random positioning machine

Structured illumination microscopy

Spatial light modulator

Selective Plane Illumination Microscopy winnok.devos@uantwerpen.be. Tel.: +32 326534 45. Fax: +32 326433 01. 
STED STORM

Stimulated emission depletion

WFM
Stochastic optical reconstruction microscopy

Widefield fluorescence microscopy

\section{RELEVANCE OF BIOLOGICAL SPACE RESEARCH}

Long-term space travel brings about significant health risks. Scarce data from astronauts and model organisms reveal a correlation of space travel with health issues such as muscle atrophy, bone loss, nerve abnormalities, immune deficiency, cataracts, and increased cancer predisposition. ${ }^{1-3}$ Next to the lack of exercise and a general increased state of stress among astronauts, the physical conditions of the space environment - in particular ionizing radiation (IR) and microgravity $(\mu \mathrm{g})$ - are considered to contribute significantly to the development of these disorders. Radiation levels in space are a hundred to a thousand times higher than on Earth. Moreover, galactic cosmic rays possess a complex spectrum of particulate radiation, consisting of fully ionized nuclei of high energy (E) and high atomic mass (Z). These so-called HZE particles deposit their energy in a highly concentrated manner and yield biological damage such as clustered DNA breaks. ${ }^{4,5}$ Severe DNA damage causes cytotoxicity in terminally differentiated cells such as neurons, but also leads to genome instability in a variety of cell types, fostering cancer development. A reduction in the gravitational force, in turn, alters body fluid flow as well as the architecture and three-dimensional organization of tissues and cells. ${ }^{6-8}$ Space experiments and ground-based simulations have also shown that both factors induce marked changes in gene expression. ${ }^{9-11}$ Despite these documented relationships, major uncertainties remain regarding the exact contribution of IR and $\mu \mathrm{g}$ to human disorders and the underlying molecular and cellular mechanisms. For instance, it is not clear to what extent HZE-induced DNA damage or $\mu \mathrm{g}$ induced cytoskeletal reorganizations persist upon prolonged exposure, if and how physical or biochemical communication between cells and within a multi-cellular organism contributes to the response, or how both factors jointly affect spatiotemporal gene expression patterns, differentiation and development. Recently, the European Space Agency's (ESA) Topical Team on Microscopy (Frankfurt, January 2014) compiled a more extensive list of fundamental biological questions in space science, of which a summary is provided in Table I.

Insight into the cellular mechanisms that become active in space is not only relevant for astronauts but also has major value for applications on Earth, for instance in cancer research. Indeed, understanding the impact of low-dose IR on DNA damage and repair kinetics will help estimating cancer risks associated with diagnostic imaging (in particular CT) and help refining estimations of individual and organ-specific radiosensitivity. Similarly, targeted irradiation of solid tumors (hadron therapy) will greatly benefit from improved insights in HZE-induced cytotoxicity and bystander effects. ${ }^{3,12} \mathrm{~A}$ third example is the utility of $\mu \mathrm{g}$ in the creation and evaluation of three-dimensional cell culture systems such as cellular spheroids. Because these three-dimensional aggre-

gates more faithfully recapitulate the physiological properties of a solid tumor, they are rapidly gaining importance in cancer-drug screening assays (cf. next paragraph). ${ }^{12}$

\section{BIOLOGICAL MODEL SYSTEMS FOR SPACE SCIENCE}

Regardless of the context (space or Earth-bound research), placing biological phenomena under close scrutiny requires apt models (Fig. 2). While mammalian model organisms such as mice yield physiologically relevant responses (90\% genetic homology with humans), they are associated with practical limitations, ethical objections, and poor statistics, especially in space. More attractive models for space biology experiments include small organisms such as Caenorhabditis elegans, Danio rerio, Oryzias latipes and small model plants such as Arabidopsis thaliana. C. elegans is an optically transparent free living nematode, which is very easy to handle and grows in the lab with minimal nutrient requirements. It has a short lifespan and is amenable to facile genetic manipulations. The organism has proven useful in space-related studies spanning aspects of development, aging, and radiobiology. ${ }^{13,14}$ Danio rerio (zebrafish) and Oryzias latipes (medaka) are popular for studying development as well as human disease, owing to their optical clarity during development, their small size, and short generation time. ${ }^{15,16}$ Dedicated facilities have been conceived for performing experiments with these model organisms in the Space Shuttle or at the International Space Station (ISS). ${ }^{17,18}$ Fundamental studies in higher plants such as Arabidopsis mainly pertain to their gravisensing properties. ${ }^{19-21}$ But, by virtue of their recycling potential in life support systems, their growth behavior is also of direct relevance for manned missions (e.g., Micro Ecological Life Support System Alternative (MELISSA)). ${ }^{22}$

Experiments with small organisms are typically expressed in terms of phenotypical changes. However, when interested in the fundamental mechanisms of a biological process, model organisms are often too complex. The alternatives are cell-based systems. Cells are the smallest integrated units in any biological system and respond in a dynamic and sensitive manner to a changing environment. They can be manipulated and have dimensions that allow one to work at extremely small scales in a statistically relevant manner. Various cellular models can be employed that range from micro-organisms to human cell cultures. ${ }^{23}$ Obviously, studies on cell-based systems can be very different from mammalian model organisms, but starting with individual cell models, one can gradually adapt more complex multi-cellular systems such as co-cultures, spheroids, and organotypic or organoid cultures.

The simplest cellular models are the rapidly growing and easily cultured and manipulated microorganisms. Both prokaryotic (B. subtilis and E. coli) as well as eukaryotic (S. cervisiae) unicellular organisms have been used to study space environmental effects. The major parameters of interest in these studies are cell growth and mutation rate. ${ }^{24,25}$ A primary driver for their use is that the radio-, particle-, and/or gravisensitivity of microorganisms may be extrapolated to mammalian cells. In this context, yeast cells have a clear advantage since many core cellular activities (cell 
TABLE I. Overview of the fundamental biological questions in space biology along with typical experimental endpoints that can be measured using microscopy approaches.

\begin{tabular}{|c|c|c|}
\hline Theme & Major topics & Experimental endpoints \\
\hline \multirow[t]{5}{*}{ Cell physiology } & Cell viability and growth kinetics & Cell number, live/dead ratio \\
\hline & Cell morphology and architecture & $\begin{array}{l}\text { Cell shape, granularity, cytoskeletal features (e.g., size and number of focal } \\
\text { adhesion points or stress fibers) }\end{array}$ \\
\hline & Cellular metabolism & Oxygen or glucose consumption rates, ATP levels, intra- and extracellular $\mathrm{pH}$ \\
\hline & DNA damage and repair kinetics & $\begin{array}{l}\text { Repair foci number or occupancy, repair protein immobilization and residence } \\
\text { time, repair complex composition, nonlinear responses (e.g., bystander effects) }\end{array}$ \\
\hline & Cellular stress and redox balance & $\begin{array}{l}\text { Reactive oxygen species and antioxidant levels, mitochondrial potential, } \\
\text { transcription factor translocation }\end{array}$ \\
\hline \multirow[t]{2}{*}{ Spatiotemporal behavior } & Gene expression patterns and regulation & Promoter activity, transcription factor translocation, protein turnover rate \\
\hline & Cell migration & Wound healing speed, cell invasion potential, chemotaxis \\
\hline \multirow[t]{3}{*}{ Cellular micro-environment } & $3 \mathrm{D}$ cell and tissue architecture & Morphology, cytoskeletal features, cell type distribution \\
\hline & Cell-cell and cell-ECM interactions & $\begin{array}{l}\text { Abundance and distribution of cell adhesion molecules, receptor interactions, } \\
\text { enzyme activation, mechanotransduction pathway activation }\end{array}$ \\
\hline & Cell-cell communication & $\begin{array}{l}\text { Gap junction abundance, synchronized cell activity (e.g., calcium signaling), } \\
\text { extracellular cytokine levels, exo-/endocytosis rates }\end{array}$ \\
\hline \multirow[t]{2}{*}{ Developmental biology } & Cell plasticity and differentiation & Morphological features, cell-lineage specific biomarkers \\
\hline & Developmental aberrations & Defects in proliferation, migration, morphology, gene expression \\
\hline \multirow[t]{5}{*}{$\begin{array}{l}\text { Diagnostic and therapeutic } \\
\text { applications }\end{array}$} & $\begin{array}{l}\text { Tissue specific and individual } \\
\text { radiosensitivity }\end{array}$ & DNA damage repair and kinetics, cytotoxicity \\
\hline & $\begin{array}{l}\text { Tissue specific and individual } \\
\text { gravisensitivity }\end{array}$ & Cytoskeletal reorganization, activation mechanotransduction pathways \\
\hline & Hadron therapy & DNA damage repair and kinetics, cytotoxicity, bystander effects \\
\hline & Tissue regeneration & 3D cell organization, morphology, differentiation \\
\hline & Countermeasures & $\begin{array}{l}\text { Any of the above in the presence of acute or chronic administration of small } \\
\text { molecules or bio-active peptides }\end{array}$ \\
\hline
\end{tabular}

cycle control, DNA repair, and post-translational modifications) closely resemble those of mammalian cells. But microorganisms are not only used to study fundamental biological processes, they are also of interest because of their waste recycling capabilities (cf. MELISSA ${ }^{22}$ ) and knowledge about microbial growth in space is directly relevant for human health protection. Indeed, several in-flight studies have reported that the microgravity environment encountered during spaceflight alters bacterial growth and physiology, antibiotic resistance, and virulence. ${ }^{24,26}$ In combination with a reduced innate immune system (as witnessed in mouse models during and after spaceflight ${ }^{27}$ ), the increased virulence in bacteria presents a significant threat to the health of the crew during long-term space exploration.

Although mammalian cell cultures are more difficult to maintain, they rely on processes that relate to human tissues. Both adherent (e.g., carcinoma cells and fibroblasts) and suspension cells (e.g., lymphocytes), primary and transformed, have been used in space and ground-based experiments to study the complex influence of a reduced gravitational force on mammalian cell growth and function, including effects on gene expression ${ }^{9,10,28}$ and cytoskeletal organization ${ }^{29,30}$ as well as the effects of cosmic radiation on DNA damage repair $^{5,11}$ and cytokine secretion. ${ }^{5,31}$ Nevertheless, most cellbased studies are being performed with individual cells, either in suspension, or as adherent monolayers cultured on hard, flat surfaces. This does not correspond to an in vivo situation. ${ }^{32}$ On the contrary, most pro- and eukaryotic cell types grow in tight connection with other cells, usually in a highly organized three-dimensional microenvironment. The majority of bacteria in nature exist in surface-associated mi- crobial communities known as biofilms and human cells typically organize themselves in tissues that consist of one or more cell types and an extracellular matrix. These threedimensional cell systems behave differently than their twodimensional or suspended counterparts. For instance, compared to isolated colonies, bacteria in biofilms often exhibit increased resistance to environmental stress, antibiotics, and host defense systems. Spaceflight has been shown to increase biofilm biomass, thickness, and three-dimensional organization compared to ground conditions. ${ }^{33}$ In this context, it is worth noting that biofilms were an abundant nuisance on the Russian Mir space station and are still a challenge on the International Space Station (ISS). Similarly, two-dimensional mammalian cell monolayers cultured on hard and flat substrates do not experience the same biochemical or mechanical cues as those found in real tissues. In fact, monolayer cell cultures lose many of their tissue-related properties rapidly, thereby reducing the physiological relevance of experiments performed with such cultures. ${ }^{32}$ Organotypic explant cultures maintain the original tissue architecture well, but are difficult to keep in culture. Growing cells in an artificial threedimensional architecture allows rescuing some of the tissue functions and therefore, improves the physiological relevance compared to two-dimensional cultures. ${ }^{34}$ Like bacterial biofilms, three-dimensional mammalian cell cultures seem to be more resistant to extraneous stressors (e.g., towards ionizing radiation ${ }^{35}$ ). Different approaches with varying complexity exist to generating three-dimensional cell cultures, several of which make use of feeder layers, collagen matrices, or other scaffolds. ${ }^{36}$ The simplest, yet powerful alternative is the use of cellular spheroids, which do not require external 
TABLE II. Comparison of pros and cons of different imaging modalities.

\begin{tabular}{|c|c|c|c|c|c|c|}
\hline & Technique & $\begin{array}{l}\text { Resolution } \\
\text { (XY-Z; nm) }\end{array}$ & $\begin{array}{l}\text { Maximal penetration } \\
\quad \text { depth }(\mu \mathrm{m})\end{array}$ & $\begin{array}{l}\text { Acquisition } \\
\text { time/image }\end{array}$ & Photo-efficiency & $\mathrm{A}=$ advantage $\mathrm{D}=$ disadvantage \\
\hline \multirow[t]{2}{*}{$2 \mathrm{D}$} & Transmission & 250 & - & $\mathrm{ms}-\mathrm{s}$ & +++ & $\begin{array}{l}\text { A : low cost and build complexity } \\
\text { D : low contrast }\end{array}$ \\
\hline & WFM & 250 & - & ms-min & ++ & $\begin{array}{l}\text { A : low cost and build complexity } \\
\text { D: Thin specimens; out-of-focus blur }\end{array}$ \\
\hline \multirow[t]{4}{*}{$3 \mathrm{D}$} & CFM & $200-400$ & 150 & $\mathrm{~s}-\min$ & - & $\begin{array}{l}\text { A : Optical sectioning } \\
\text { D : Scanning }\end{array}$ \\
\hline & $\begin{array}{l}\text { Spinning } \\
\text { Disk CFM }\end{array}$ & $200-400$ & 50 & ms-min & + & $\begin{array}{l}\text { A : Speed } \\
\text { D: Fixed pinhole }\end{array}$ \\
\hline & MPM & $300-500$ & 1000 & $\mathrm{~s}-\min$ & - & $\begin{array}{l}\text { A : Penetration depth; inherent confocality } \\
\text { D : High power pulsed laser }\end{array}$ \\
\hline & LSFM & $250-500$ & $>1000$ & $\mathrm{~ms}-\mathrm{s}$ & +++ & $\begin{array}{l}\text { A : Low phototoxicity and isotropic } \\
\text { resolution } \\
\text { D : Sample preparation; image data size }\end{array}$ \\
\hline \multirow[t]{2}{*}{ Superresolution } & STED & $80-400$ & 50 & $\min$ & -- & $\begin{array}{l}\text { A : Superresolution at confocal speed } \\
\text { D : Intense depletion laser; dye compatibility }\end{array}$ \\
\hline & STORM & $50-100$ & 0.1 & $\min -\mathrm{h}$ & -- & $\begin{array}{l}\text { A : Extremely high resolution } \\
\text { D : Pointillism artifacts and slow speed }\end{array}$ \\
\hline \multirow[t]{3}{*}{$\begin{array}{l}\text { Molecular } \\
\text { Techniques }\end{array}$} & $\begin{array}{l}\text { Photo- } \\
\text { conversion }\end{array}$ & 150 & - & ms-min & - & $\begin{array}{l}\text { A : In situ molecular dynamics } \\
\text { D : Laser intensity ; high dye concentration }\end{array}$ \\
\hline & FLIM & 250 & - & $\mathrm{ns}-\mu \mathrm{s}$ & - & $\begin{array}{l}\text { A : Local biochemical environment and } \\
\text { interactions } \\
\text { D : High repetition rate (time gated) or } \\
\text { frequency modulation }\end{array}$ \\
\hline & FRET & $4-10$ & - & $\mathrm{ms}-\mathrm{s}$ & - & $\begin{array}{l}\text { A : Molecular interactions } \\
\text { D: Confounding factors (conformation, } \\
\text { pH...) }\end{array}$ \\
\hline
\end{tabular}

scaffolds and can be obtained from many different cell types by seeding cells in hanging drops or on non-adhesive cellrepellent) surfaces. They can also be generated by employing tools that simulate $\mu \mathrm{g}$ such as random positioning machines or rotating wall vessels. ${ }^{37,38}$ In space, spheroids form spontaneously. Because cells in real $\mu \mathrm{g}$ do not experience fluid shear (which is typically present in $\mu \mathrm{g}$ simulations), it has been proposed that biochemical cues are the main drivers for their aggregation. ${ }^{8}$ Cells grown in spheroid cultures have a markedly different physiology than when grown in monolayers. For instance, ovarian tumor spheroids are more resistant to antineoplastic drugs ${ }^{39}$ and human mesenchymal stem cell (hMSC) spheroids have an enhanced osteogenic and adipogenic potential compared to their resp. two-dimensional counterparts. ${ }^{40}$

\section{STATE-OF-THE-ART IN ADVANCED LIGHT MICROSCOPY}

A thorough understanding of cellular processes inevitably calls for microscopic visualization methods. In this paragraph, we review the properties of different imaging modalities in a non-exhaustive manner and discuss their relevance for space-related research. Table II summarizes some of the properties of these modalities and Figure 1 compares the typical spatiotemporal scales, at which they operate. Representative examples of images that can be obtained with some of the presented microscopy techniques on typical model systems are shown in Figure 2.

\section{A. Two-dimensional light microscopy}

A simple but essential modality for visualizing cells is transmitted light microscopy as it reveals a number of cellular features such as cell morphology and granularity, which can be used to discriminate various cell types or cell states (cell cycle, differentiation, and apoptosis). It can also be applied in a number of important household monitoring tasks such as gauging cell culture density and contamination (bacterial or fungal infections) or finding a cell culture's substrate contact in a non-phototoxic and label-free manner. In its most basic form, such an imaging mode has low conception complexity, but since cells are thin, transparent, and contain few light-absorbing components, contrast is often poor. Therefore, several extensions have been devised to increase the contrast, which are mainly based on converting phase differences into amplitude differences. Examples include Zernike phase contrast or Nomarski differential interference contrast (DIC) microscopy. These methods rely on the introduction of phase retarding or beam-shearing components, respectively, in conjugate planes of the illumination light path (condenser front focal plane and objective back focal plane) and subsequent interference of the emanating light bundles. Recent developments based on lateral shearing interferometry do not require 


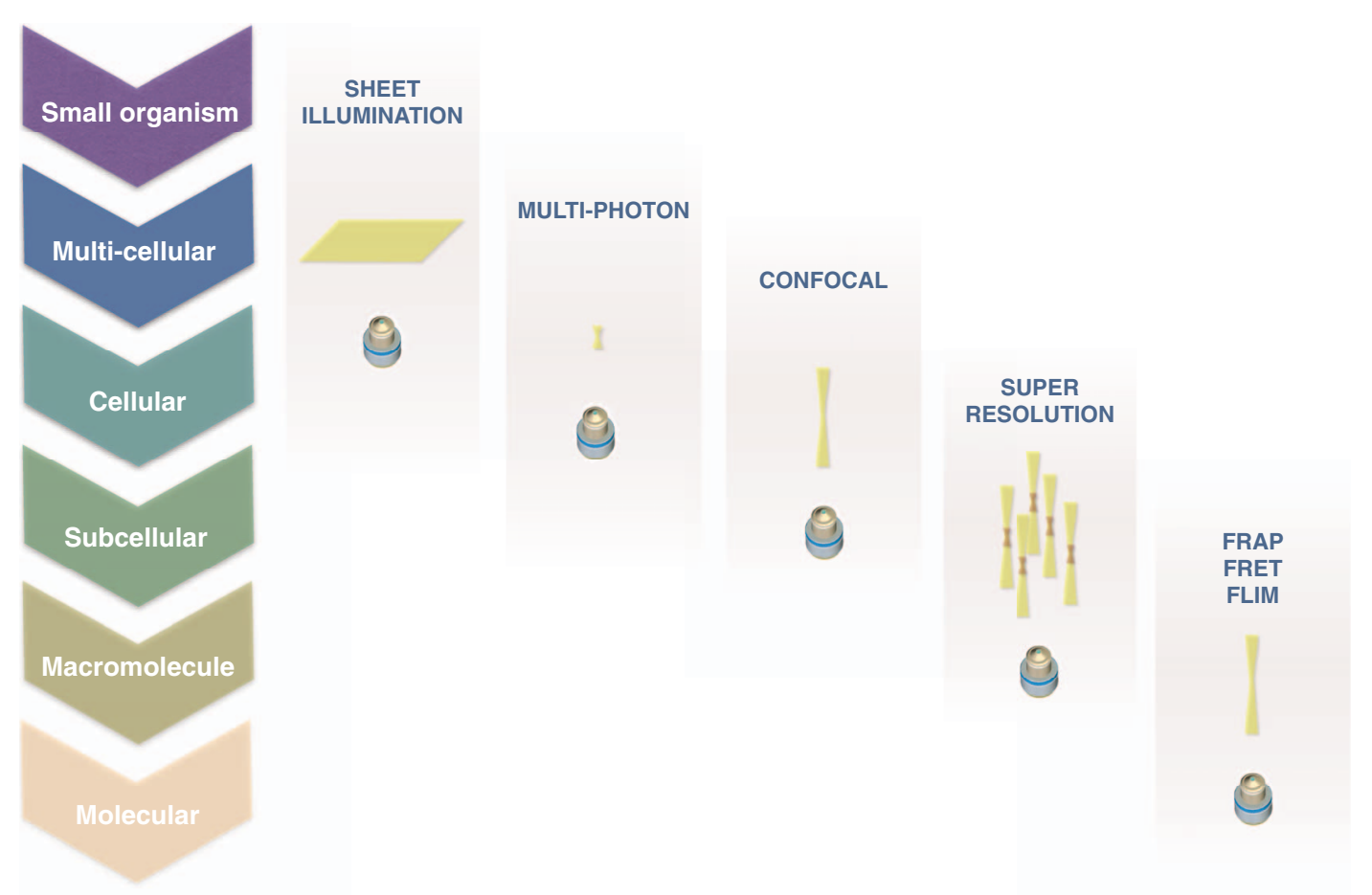

FIG. 1. Summary of major microscopy modalities and the biological scales at which they typically (but not exclusively) operate.

such interventions, but instead act on the detector. ${ }^{41}$ Whilst such quantitative phase imaging methods expand applications to real-time follow-up of cellular dry mass and intracellular dynamics of specific organelles such as lysosomes ${ }^{41}$ transmission microscopy remains limited when it comes to monitoring subcellular processes, despite its excellent sensitivity and speed. The major reasons for that are the high transparency of typical biological samples (e.g., cells) and the lack of specific dyes for identifying specific proteins or chromatin structures. This is where fluorescence has become an invaluable asset. Conventional, widefield fluorescence microscopy (WFM) allows visualization of subcellular features with high precision and contrast; either directly through the excitation of endogenous, autofluorescent components, or indirectly, using exogenously administered labels. Autofluorescent cellular components (e.g., chlorophyll, NADH, collagen, and lipofuscins) do not require any extraneous markers and serve as reliable natural cell state indicators, since the emission often changes with cellular metabolism or in response to external and internal impulses. ${ }^{42-44}$ The obvious advantage of autofluorescent molecules is their non-invasive character, but unfortunately, only few such molecules exist. Hence, cellular components are most often labeled. While in the past this was done using organic dyes, the discovery and cloning of the green fluorescent protein (GFP) has revolutionized the field, allowing virtually any protein to become fluorescently tagged. ${ }^{45}$ This way, it has become straightforward to follow the spatiotemporal distribution of genetically encoded fusion proteins in living cells. Moreover, directed mutations of the GFP gene and the discovery of other fluorescent proteins provide an entire toolbox of fluorescent proteins with various spectroscopic as well as sensor characteristics. ${ }^{46,47}$ Fluorescent protein technologies have many applications in cell bi- ological space research, among which as a tool for studying environmentally regulated gene expression reporting on cell survival $^{48}$ or cellular stress response. ${ }^{49}$ In the field of radiobiology, fluorescent fusion proteins enable real-time follow-up of DNA repair in living cells, which helps to generate insights in cellular pathways involved in HZE interception. ${ }^{50,51}$ The use of fluorescent proteins is not limited to individual cells but is readily expanded to small organisms, e.g., to investigate redox biology in C. elegans ${ }^{52}$ or cytoskeletal organization or root hair development in A. thaliana. ${ }^{53,54}$ A potential drawback of fluorescent labels is that one always visualizes the (overexpressed) probe and not the endogenous molecule of interest. This alters the cell physiology: some dyes act as chelators for small molecules or intercalate in essential structures such as DNA. Similarly, GFP moieties may mask localization signals or interfere with proper folding of the protein to which they are coupled. Optimization of protocols with proper controls and a comparison with native biological systems is, therefore, essential.

\section{B. Three-dimensional light microscopy}

WFM has very poor axial resolution and suffers from out-of-focus blur and scatter. Deconvolution tries to tackle this problem mathematically, by reconstructing the image using information on the image formation process. However, this approach is highly dependent on the accuracy of the calculated or pre-determined point-spread-function (PSF) and quickly loses its performance in the presence of noise. ${ }^{55}$ Confocal fluorescence microscopy (CFM) combines point illumination with point detection. Point illumination is achieved via a diffraction-limited laser and point detection occurs through an aperture in front of an intensity detector. By design, CFM 

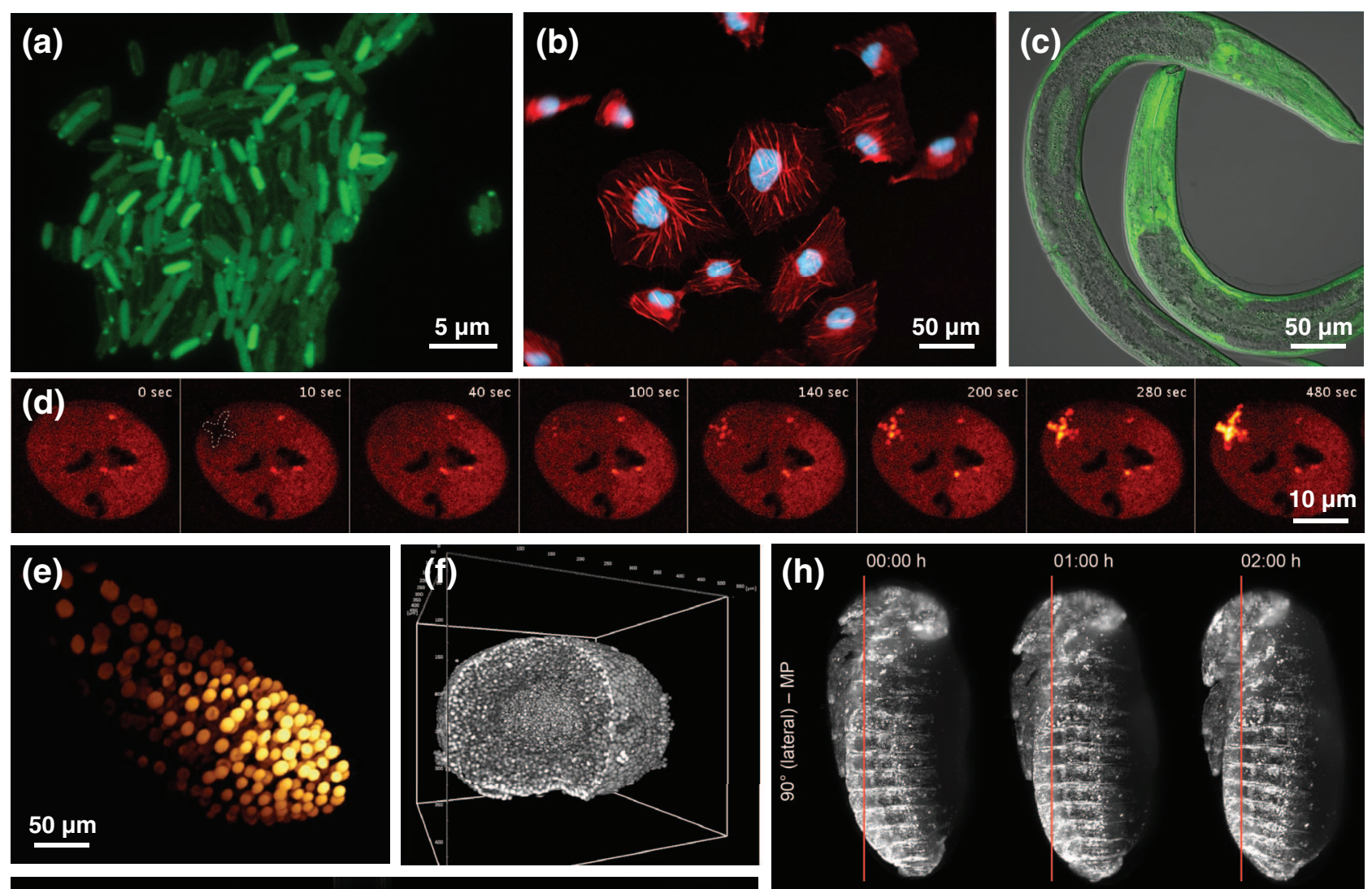

$02: 00 \mathrm{~h}$
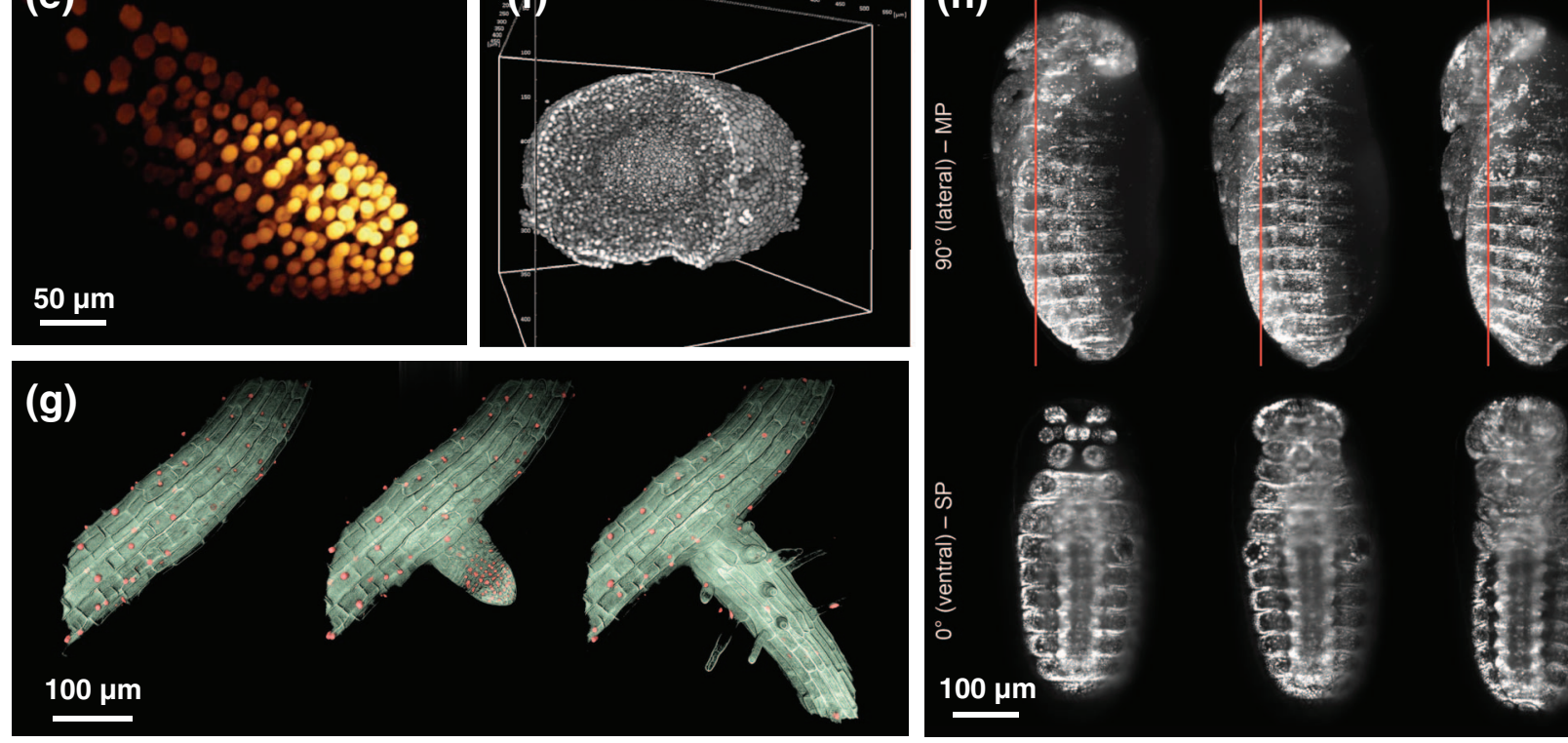

FIG. 2. Representative images of various biological samples acquired with different microscopy modalities. (a) Widefield acquisition of an Escherichia Coli colony stably producing free EGFP (at variable levels); (b) Widefield acquisition of HeLa cells counterstained with the nuclear dye DAPI (blue) and the fluorescently labeled actin-binding drug phalloidin (red). Note the prominent stress fibers, due to growing the cells on a glass substrate; (c) Caenorhabditis elegans strain bearing the genetically encoded fluorescent biosensor HyPer for intracellular detection of hydrogen peroxide (generated in the lab of Professor Braeckman. ${ }^{52}$ ). Merged image of a simultaneously acquired DIC acquisition (grey) and a confocal section (green); (d) Time sequence from a localized microirradiation experiment on a U20S-53BP1-GFP cell nucleus showing the time-dependent accumulation of 53BP1-GFP after local irradiation with near UV (405 $\mathrm{nm}, \sim 30 \mu \mathrm{J} / \mu \mathrm{m}^{2}$ ) in a cross region (delineated in white in the $10 \mathrm{~s}$ time point). More intense nuclear foci that are present before irradiation represent regions where spontaneous DNA damage has occurred (cell line was a kind gift from Professor M. Durante ${ }^{51}$ ); (e) Three-dimensional volume rendering of a root tip from a transgenic Arabidopsis thaliana plant, stably producing fluorescent nuclear H2B-GFP fusion proteins. Image data set acquired with a confocal microscope; (f) Three-dimensional volume rendering of a prolate spheroid seeded with about 10000 cells, stained with the nuclear dye Draq5. A quarter of the volume recording was not visualized to show the spheroid's necrotic core. Image data set acquired with DSLM (image by Christian Mattheyer and Francesco Pampaloni); (g) Volume rendered view showing the emergence of the lateral root from the primary root in a transgene Arabidopsis thaliana plant at 3 of in total 350 time points of a 90 h DSLM recording. Plasma membranes are labeled in green (35S::LTI6b-GFP) and nuclei in red (35S::H2B-RFP) (image by Daniel von Wangenheim and Alexander Schmitz) ${ }^{54}$ (h) Optical sections through a Tribolium castaneum embryo acquired with DSLM. The embryo expresses a nuclear localized GFP under the control of the ubiquitous EF1A1 promotor. The top row show the $90^{\circ}$ (lateral) maximum projections (MP) of three time points during dorsal closure. During this process, the head turns approximately $45^{\circ}$ from an anterior to an anterior-ventral orientation. The red bar indicates the location of the $0^{\circ}$ (ventral) single planes (SP) that are shown in the bottom row. The single planes are taken at a depth of $65 \mu \mathrm{m}$, showing internal head structures from different angles. Based on a figure from Strobl et $_{\text {al. }}{ }^{67}$

provides optical sectioning and the capability to construct a three-dimensional representation of the fluorophore distribution in a biological sample. ${ }^{56}$ The use of scanning inevitably makes CFM slower than WFM, with typical pixel dwell times in the order of 5-10 $\mu$ s. In live cell imaging, rapid cellular processes may not be adequately sampled. To speed up acquisition, multipoint/tandem confocal scanning methods have been devised, such as the Yokagawa spinning disk, sweptfield or line scanning microscopy, but they all suffer from compromises in optical sectioning performance (due to spatial crosstalk) and are limited to relatively thin samples (because of scattering). A more recent alternative is based on the use of a pixelated device called spatial light modulator (SLM) that is positioned in an intermediate image plane. Microscopes that 
make use of an SLM are also referred to as programmable array microscopes. The SLM consists of individually addressable digital micro-mirrors or liquid crystal-on-silicon microdisplays that can be programmed to generate a wide spectrum of user-defined illumination and detection scenarios. ${ }^{57}$ If the illumination and conjugate detection pattern is sparse, the image will be optically sectioned.

Optical sectioning is not only attractive for investigations of subcellular processes in their three-dimensional context, but also for multilevel acquisitions. This is needed in case of suspension cells held in different positions or for imaging thick or irregular specimens such as tissue sections, bacterial biofilms, plant material and small organisms. However, due to absorption and scattering of the illumination light and the use of high numerical aperture (NA) objectives with short working distance, the penetration depth of CFM is typically limited to about $100-150 \mu \mathrm{m}$. Low NA lenses have longer working distances but this at the expense of their sectioning performance. Since longer wavelengths experience less scattering, they allow deeper tissue penetration. By using infrared pulsed lasers, multi-photon microscopy (MPM) is able to reach up to $1 \mathrm{~mm}$ in a sample. ${ }^{58,59}$ The technique relies on the fact that two (or three) photons with a long wavelength transfer the same energy, as a single photon with half (or a third of) that wavelength, provided the intensity and hence the excitation probability are sufficiently high. ${ }^{60}$ Therefore, MPM systems require a relatively high numerical aperture $(>0.7)$ and a short laser pulse. Typically, Ti:Sapphire lasers are used that emit short pulses of around $100 \mathrm{fs}$ at high frequency $(80 \mathrm{MHz})$. Since the probability of efficient excitation is limited to the focal plane, this technique is inherently confocal. However, the laser powers are very high, the excitation efficiency is low and the recording times are longer than with a CFM.

A completely different approach to optical sectioning is used in light sheet-based fluorescence microscopy (LSFM), where the sample is illuminated from the side, i.e., perpendicular to the acquisition path, with a focused plane of light. Since no fluorophores are excited outside of the illuminated plane, LSFM provides intrinsic optical sectioning capability. With exposure being limited to a thin plane and fluorescence of the entire field of view being detected at once (using a CCD camera), photobleaching is reduced by two to five orders of magnitude compared to WFM, CFM, and MPM. ${ }^{61,62}$ A widely adopted implementation, termed Selective Plane Illumination Microscopy (SPIM), uses a cylindrical lens to turn an incoming laser beam into a light sheet. ${ }^{63}$ Alternatively, the light sheet is generated by rapidly scanning a $\mu \mathrm{m}$-thin laser line in the vertical direction through the biological specimen during the exposure time (Fig. 3(b)). This approach was coined digitally scanned light sheet-based fluorescence microscopy (DSLM) ${ }^{64}$ Because no beam-shaping units are required, illumination efficiency is very high ( $>95 \%)$ and laser powers can be reduced. Although slower than SPIM, DSLM still surpasses CFM by a factor of 100 in terms of pixel dwell time for the same acquisition rate. ${ }^{65}$

Because of its photo-efficiency and the lower NA that is typically used on the illumination side, LSFM methods are well suited for imaging deep within transparent or chemically cleared whole organisms (in toto imaging). Sheet il- lumination is now the method of choice for developmental studies of model organisms such as zebrafish ${ }^{64}$ Drosophila melanogaster ${ }^{66}$ or Tribolium castaneum ${ }^{67}$ and has also been applied to the study of Arabidopsis thaliana root growth ${ }^{54}$ or cellular spheroids. ${ }^{37}$ The technology is also continuously being improved to obtain better image quality, acquisition speed, and/or spatial resolution. Image quality in a standard FLSM setup (as in any other microscopy approach) can be degraded by opaque structures causing scattering and absorption, especially in deep tissue. This respectively leads to spreading of the light sheet (and adjoined out-of-focus blur) and shadow artifacts. Imaging the sample from different angles, while rotating the sample around its axis effectively reduces shadowing but leaves scattering unresolved. To address this issue, setups have been devised in which the sample is illuminated from two sides, either simultaneously, such as in ultramicroscopy, ${ }^{68}$ or sequentially, such as in multidirectional SPIM (mSPIM) ${ }^{69}$ Alternative ways to remove out-of-focus light are based on combining DSLM with structured illumination patterns ${ }^{70}$ (see section on superresolution) or confocal slit detection. ${ }^{71,72}$ Further improvements have been achieved with two-photon excitation ${ }^{73}$ and/or Bessel beams. ${ }^{74,75}$ These non-diffractive beams successfully maintain their shape and size at larger penetration depths ${ }^{76}$ and have also been used to generate thinner light-sheets. ${ }^{75}$ Next to methods that improve deep tissue penetration and image quality, various developments have focused on boosting acquisition speed. For example, an elegant method has been proposed to allow simultaneous acquisition of multiple focal planes onto a single large sensor using a multifocus grating. ${ }^{77}$ Multiview imaging can also be obtained by splitting the fluorescence light and directing it into separate detection light paths towards multiple cameras. ${ }^{66,78}$ Yet another strategy consists of simultaneous excitation of multiple planes using spatial filtering ${ }^{79}$ and rapid axial scanning, for instance assisted by an electronically tunable lens. ${ }^{80}$

\section{Time-lapse microscopy}

Following cells over time provides information on, e.g., protein turnover, organelle mobility, cellular migration, cell division, and differentiation. All the aforementioned microscopy methods in principle allow imaging time-dependent processes, but in order to study living cell systems in a physiologically relevant manner, several additional conditions need to be met. First, the cellular environment needs to be meticulously controlled, in particular $\mathrm{pH}$, temperature, and nutrient supply. This is a particularly demanding challenge in space flight where resources are very limited. Environmental control is the principal task of the life support system but also puts constraints on the imaging system. For instance, temperature gradients between the cell sample and the imaging device should be minimized to avoid excessive condensation or focus drifts. To cater for technical focus variations, hardware-driven autofocus technologies exist. Provided all environmental conditions are optimal, a major concern that remains is the illumination itself. Intense light irreversibly damages fluorochromes and thereby reduces the effective fluorescence in the 
(a)

\section{BACK}

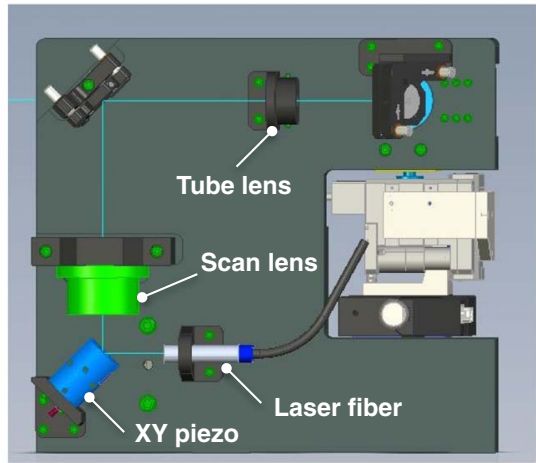

FRONT

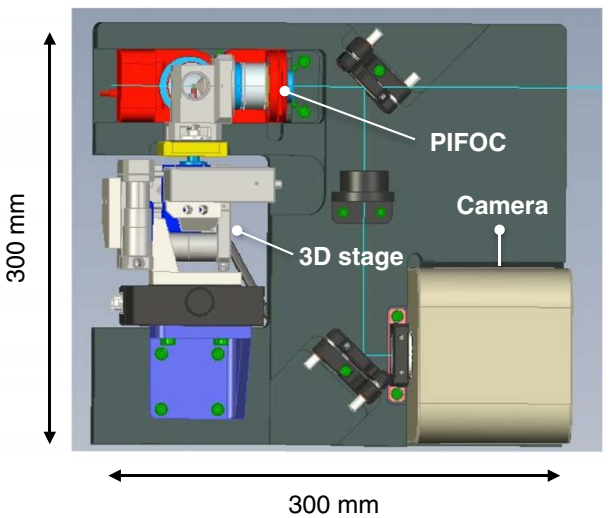

TOP

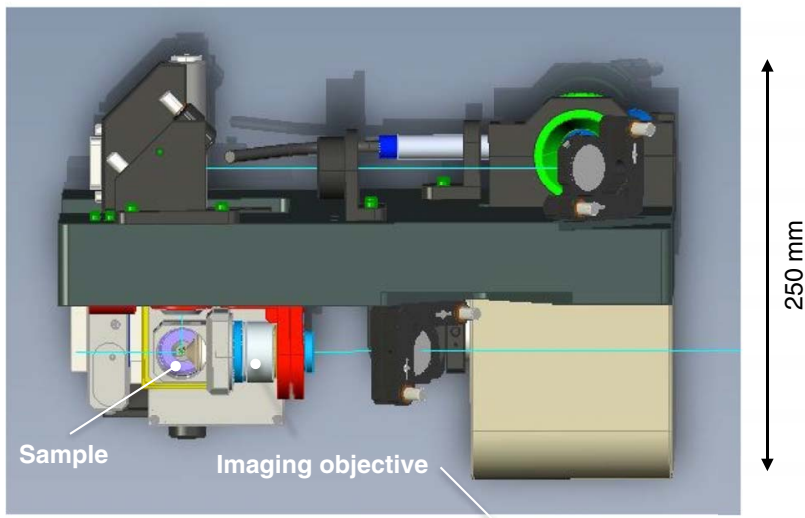

SIDE

Illumination objective

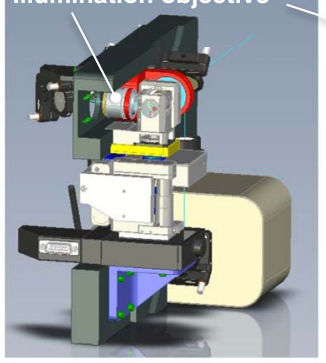

SAMPLE HOLDER

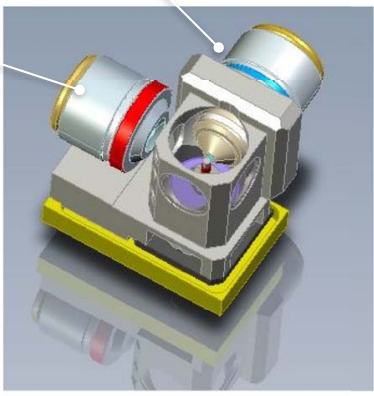

$E$
E
ํㅐ

(b)

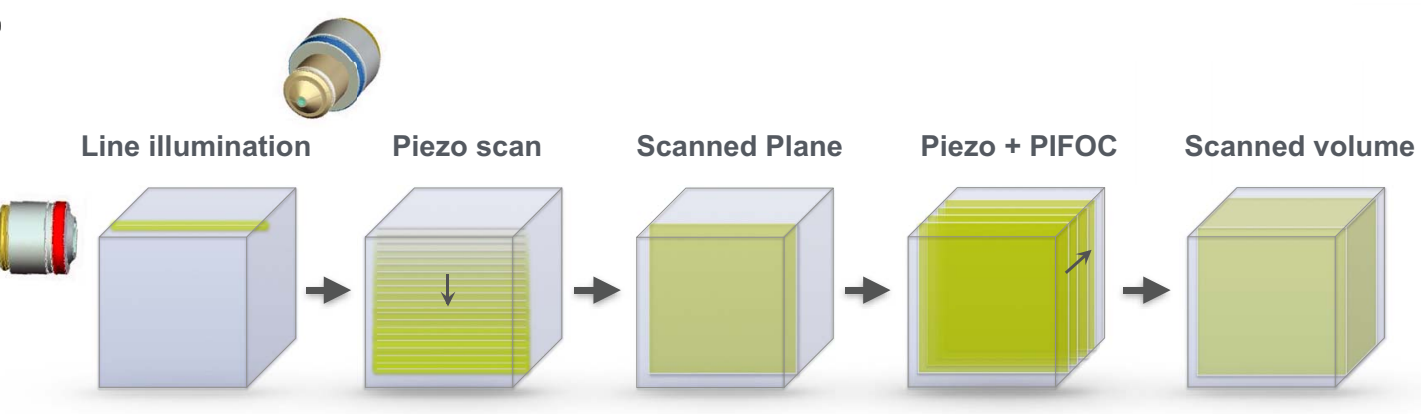

(c)

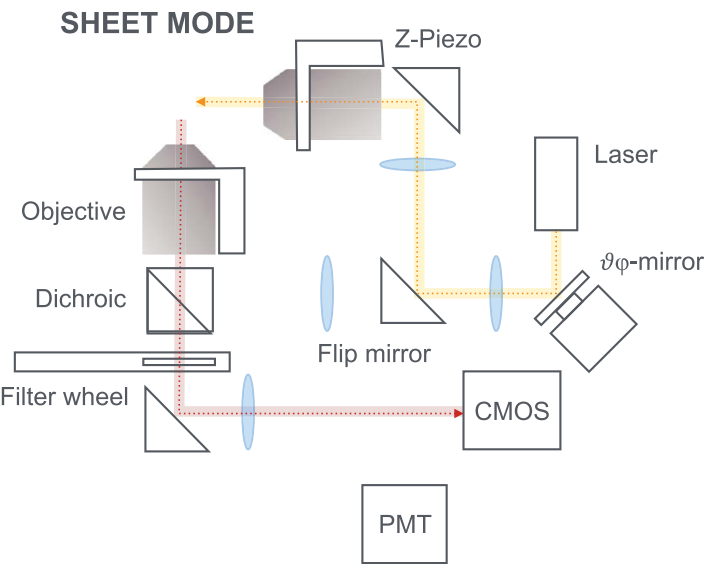

EPI MODE

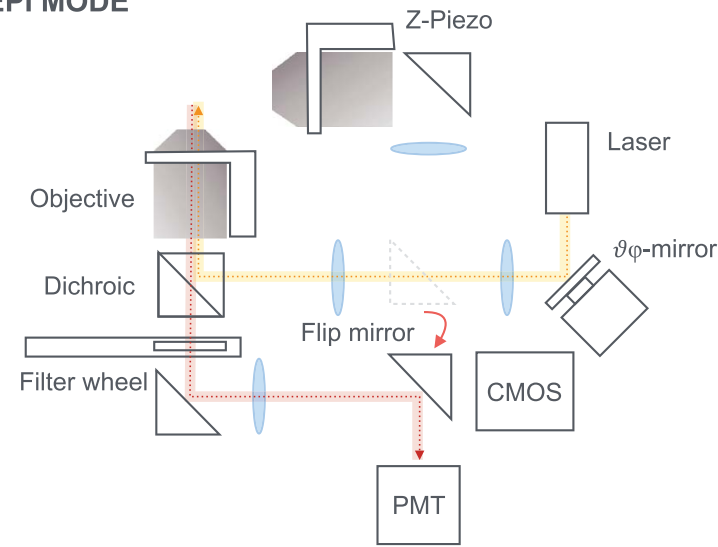

FIG. 3. DSLM concept for biological space research. (a) Model of a compact DSLM with orthogonal illumination setup including sample holder, visualized from different angles. (b) DSLM illumination sequence: the illumination objective rapidly scans a laser line through the sample in the axial direction, thereby generating an illumination sheet. This illumination scheme is combined with a rapid displacement of the sample using a piëzo-driven three-axis motorized stage and synchronized movement of the objective by a piëzo-driven nano-positioning focus device (PIFOC). The combination of axial scanning and lateral displacement allows for sampling the complete volume; (c) Schematic illustration of the DSLM light path, equipped with a flip-mirror to allow switching between sheet illumination and CFM mode using the same equipment. 
illuminated region. This phenomenon is called photobleaching and is typically associated with the production of reactive oxygen species, which interact with various biological molecules causing damage or phototoxicity. Photobleaching and phototoxicity are jointly referred to as photodamage. Whereas photobleaching is a burden for all fluorescence imaging, whether samples are inanimate or not, phototoxicity is the true limiting factor in live cell imaging and urges for the use of very conservative imaging conditions. The most straightforward way to mitigate photodamage is to reduce the illumination either in time or in space. Temporal modulation can simply be done by limiting the total imaging duration or increasing the illumination interval, but more nifty ways to improve photostability involve the use of pulsed excitation with low repetition rates $(<1 \mathrm{MHz}){ }^{81}$ This ensures complete relaxation of the dark states (including the triplet state with life times $>1 \mu \mathrm{s}$ ) between subsequent excitation pulses and may increase the fluorescence signal yield up to a factor of 25. An example of spatial modulation is Controlled Light Exposure Microscopy, which limits illumination to the regions of interest by brief pixelwise illumination and feedback to the light source. ${ }^{82,83}$ The aforementioned approaches only limit the exposure in the lateral sense. MPM reduces non-focal excitation but requires high power and remains quite slow. When taking the axial dimension into account, LSFM clearly becomes the most photo-efficient technology, as it restricts the illumination to the optical plane that is detected.

\section{D. (Macro-) molecular imaging}

In the slipstream of the booming live cell imaging and fluorescent protein technology, a plethora of methods has been developed to gain quantitative information about subcellular and (macro-) molecular dynamics and interactions. Many of these methods are based on selective photobleaching. By irreversibly bleaching a small region of interest (ROI) within the field of view and subsequently monitoring the recovery of the fluorescent signal within this ROI, one can extract quantitative information on the diffusion kinetics and sequestration (immobilization) of the molecule of interest. This is the principle of Fluorescence Recovery After Photobleaching (FRAP) ${ }^{84}$ There are many methods that rely on the same setup, which return complementary information. ${ }^{85}$ This increases the relevance of a photo-manipulation setup a fortiori. A couple of examples are

- Fluorescence Loss In Photobleaching (FLIP): ${ }^{86} \mathrm{~A}$ technique whereby a small ROI is repetitively bleached, while the signal in a non-overlapping ROI is continuously monitored so as to probe continuity between the bleached and non-bleached region.

- Fluorescence Localization After Photobleaching (FLAP): ${ }^{87} \mathrm{~A}$ technique in which the same protein is separately tagged with two different fluorescent proteins. When both are co-expressed in the same cell, photobleaching one of the fluorophores in a subregion allows visualizing a selected pool of monochromatic fusion proteins within a dual colored reference framework.
- Photo-conversion: A collective term for the photoinduced activation, quenching or spectral shifting in fluorescence of a fluorescent protein. ${ }^{88-90}$ Photoconversion is also known as molecular highlighting. Alike FLAP, this technique allows for studying protein mobility within a reference framework, but with only one fluorescent protein instead of two. It can also be used to study protein turnover, as an optical equivalent of pulse labeling. ${ }^{85}$ The term photo-activation may also refer to light-induced release of a caging group from a chemically masked molecule (such as a fluorochrome). ${ }^{91}$

- Förster Resonance Energy Transfer (FRET) by donor or acceptor photobleaching: A variant of the fluorescent technique for probing molecular interactions ${ }^{92-94}$ (see further down).

A fluorophore is characterized by not only its spectral characteristics but also its fluorescence lifetime. The lifetime refers to the average period of time a fluorophore remains in the excited state (typically in the nanosecond range). The advantage of measuring fluorescence lifetime instead of intensity is that it is independent of fluorophore concentration or light-path length, conditions that are difficult to control inside a cell. Fluorescence lifetimes can be determined and spatially mapped using a WFM or a CFM either in the time domain or in the frequency domain. In the time domain, the fluorescence lifetime is directly measured (e.g., with a gated image intensifier) by pulsed excitation. In the frequency domain, the lifetime is calculated from the modulation depth in sample fluorescence upon excitation with a sinusoidally modulated phase shifted light source. Fluorescence lifetime imaging microscopy (FLIM) is a sensitive technique with low detection limit, which allows the excitation at low intensities and thus better preserves the viability of live specimens. In addition, fluorescence lifetime is sensitive to changes in $\mathrm{pH}$, calcium concentration, and molecular interactions, rendering it a useful reporter of the local environment. ${ }^{95}$

A quantitative microscopy approach that allows to probe the proximity well beyond the resolution limit is FRET. ${ }^{96,97}$ FRET relies on the non-radiative transfer of energy between an excited (donor) fluorophore and a nearby (acceptor) fluorophore with matching absorption spectrum. Since the efficiency of energy transfer decreases with the 6th power of the distance between two molecules, FRET is ideally suited for measuring molecular interactions $(1-10 \mathrm{~nm})$. In addition, several FRET-based biosensors have been established that allow to probe $\mathrm{pH}$, levels of second messengers $\left(\mathrm{Ca}^{2+}, \mathrm{cAMP}\right)$, specific phosphorylation events and protease cleavage. ${ }^{98,99}$ This demonstrates a broad application range. In its simplest but least sensitive form, the detection of a FRET signal comes down to the measurement of donor and acceptor signals with respect to control samples (sensitized emission or ratio imaging). More refined (and thus more sensitive) methods rely on donor/acceptor photobleaching ${ }^{92-94}$ or donor life-time measurements. ${ }^{100}$ In theory, FRET requires an overlap of donor emission and acceptor excitation spectra, but the efficiency of FRET also depends on the local environment and the conformations of the proteins within the complex. 
Moreover, alternative technologies have been developed such as Bimolecular Fluorescence Complementation (BIFC), which demands measurement of only one single wavelength. ${ }^{101,102}$ The technique is based on the irreversible association of two non-fluorescent fragments of a fluorescent protein that reconstitute its fluorescent capacity. It is ideally suited for detection of weak or transient interactions.

\section{E. Superresolution}

The 100-fold mismatch between the resolution of an optical microscope (limit at $\sim 200 \mathrm{~nm}$ ) and the dimensions of molecular complexes hinders direct observations of molecular processes within cells. In recent years, a number of ingenious methods have been devised to circumvent the diffraction limit and thereby obtain a higher resolution. Very roughly speaking, these superresolution methods either make use of photophysical properties of the fluorophores to generate sparse emitters in conjunction with sub-pixel localization algorithms (e.g., photo-activation localization microscopy (PALM), ${ }^{103}$ stochastic optical reconstruction microscopy (STORM), ${ }^{104}$ and ground state depletion imaging (GSDIM) ${ }^{105}$ ) or they are based on nonlinear effects to effectively shrink the pointspread function (e.g., 4Pi microscopy ${ }^{106}$ and stimulated emission depletion microscopy (STED). ${ }^{107}$ ) Recently, these techniques and their variants have been compared in several excellent review articles. ${ }^{108,109}$ Despite their spatial localization (reportedly as low as $20 \mathrm{~nm}$, but realistically in the range of 50-90 nm), most approaches require specific photo-convertible probes and put a fairly high-energy load on the biological sample, rendering them less attractive for live cell imaging. Nevertheless, various time-dependent processes have been successfully visualized with both PALM and STED. ${ }^{110,111}$ Initially, superresolution approaches were limited to fairly thin samples and cell surfaces, but recently 3D imaging capabilities have been extended to much thicker samples. Taking advantage of the superior illumination confinement, signal-to-noise ratio and penetration depth of sheet illumination, localization-based superresolution has been successfully applied to cellular spheroids. ${ }^{112,113}$ Similarly, SPIM has been combined with STED to visualize actin cytoskeleton in developing zebrafish embryos. ${ }^{114}$ Next to the aforementioned methods, it is also possible to reconstruct a highresolution image, by acquiring multiple images with patterned illumination fields of different phases and orientations. This is the principle of structured illumination (SIM). ${ }^{115}$ While allowing only a modest increase in resolution (max. factor 2), SIM does not depend on any complex photo-physics or photochemistry of the fluorophore. A simplified version of SIM, requiring only three images obtained by shifting a grating in a conjugate plane, can also be used to define the in focus plane and reconstructing optically sectioned images from WFM acquisitions. ${ }^{116}$

\section{FUTURE SPACE MICROSCOPY}

Until now, most space experiments relied on post-flight image acquisition approaches. Such experiments are inherently limited in temporal resolution, causing transient events to be missed. Future space research should address dynamic cellular responses to radiation and microgravity (a) in realtime and (b) in the long-term. This is where an on-board microscopy module will significantly advance the field. The requirements for such a microscope (Table III) are primarily determined by the biology under investigation. As described in the Introduction (Table I), dynamic biological processes that are of relevance occur on different time and size scales. Cellular events such as differentiation or migration may take days or weeks, whereas subcellular processes such as DNA repair or cytoskeletal remodeling act within hours, and macromolecular events such as mobilization/translocation of DNA repair proteins, second messengers or transcription factors typically occur on the sub-second-to-minute time scale. Therefore, a space microscope should have versatility as a key feature. However, when considering the weight and volume limitations space experimentation typically imposes, it becomes clear that compactness is in fact an equally important determinant.

To answer the need for on-board microscopy, breadboards and flight models have been developed that try to

TABLE III. Minimal requirements for a high-end light microscope for biological space research.

Label-free image (focus, culture condition)

Fluorescence

Adherent and suspension cells

3D imaging

Deep tissue or multi cell layer imaging

Subcellular resolution

Prolonged live cell imaging

Automation

Multiplexing

Flexibility and simplicity

Photo-manipulation (bleaching, activation)

Data storage and transfer

Compatibility with ground-based experiments

Sample housing

Weight and volume constraints
Diascopic or reflection mode, detector

WFM, strong light source, filters, detector

Solid sample holder, Z-positioning

CFM or equivalent

Long working distance, long wavelength, MPM or FLSM

High NA (>0.6) objectives

Min. illumination, sensitive detector, autofocus, environmental control

Automated XY-stage, Z-stage, electronic shutters, software

Multi-well or cellular micro-array compatibility

Modular build, intuitive software, solid-state light source, robust alignment, small physical footprint Focused laser beam

Standard PC specifications (most calculations are done remotely), download capacity

Small physical footprint, vibration resistance

A system to accommodate multiple samples compatible with the stringent space environment Max. $\sim 30 \mathrm{~kg}$, Middeck locker size 
take these criteria into account. One of the established systems is the Light Microscopy Module (LMM) ${ }^{117}$ on the International Space Station (ISS). LMM features a commercial microscope body, configured to operate semi-automatically with remote control or astronaut assistance, and supports different illumination modes, including brightfield, darkfield, DIC and epifluorescence. ${ }^{117}$ Its modular design should allow for expanding the existing imaging capabilities with a (spinning disk) confocal unit and optical tweezers, a highly focused laser beam that can physically hold and move microscopic dielectric objects. Until now, LMM has primarily been used for fluid physics experiments, but proof-of-principle experiments with biological samples such as cell cultures and C. elegans are planned. The Japan Aerospace Exploration Agency (JAXA) has developed a system with similar features (transmission, fluorescence, and remote control) for the Japanese Experiment Module Kibo. ${ }^{118}$ The microscope is integrated within a High-Efficiency Particulate Air (HEPA)filtered glove box called Clean Bench to prevent contamination. With an eye on more advanced imaging modalities, a high-end confocal microscope has been built on a breadboard within the framework of ESA's General Support Technology Program. ${ }^{119}$ Advanced Microscopy Methods (AMME) enables live cell three-dimensional fluorescence imaging and molecular-scale techniques such as FRAP and FLIM. LMM, JAXA's Clean Bench microscope, as well as the AMME breadboard model offer a range of on-board imaging modalities and fit within a standard rack on the ISS. An important caveat is that they do not readily comply with the demands of properly controlled experiments. Indeed, to correct for variables regarding the travel and ambient conditions (e.g., launch vibrations, accelerations, air pressure, and temperature fluctuations) identical experiments should be run in parallel during ground-based simulations. This includes experiments with particle accelerators for mimicking HZE irradiation, ${ }^{120}$ vibration tables that reproduce the vibration spectrum, ${ }^{121}$ and random positioning machines (RPM) ${ }^{122}$ or large diameter centrifuges (LDC) ${ }^{123}$ that respectively cancel out or increase the gravitational force. Short-term gravitational experiments can also be performed in drop-towers and parabolic flights. Similarly, in space, experiments should be duplicated within an on-board centrifuge to evaluate the specific contribution of different gravitational forces, such as $\mu \mathrm{g}$ and intermediate Martian or lunar g-levels. ${ }^{124}$ Only by integrating information from all these controls, will we obtain a better understanding of the true contribution of individual parameters to the cellular response. This requires compatibility of the microscope setup with the dedicated infrastructure. Anticipating this issue, centrifuge microscopes have been devised such as the slow rotating centrifuge (NIedergeschwindigkeits ZEntrifugen Mikroskop, NIZEMI), ${ }^{125}$ the centrifuge for ciliates (CECILIA) ${ }^{126}$ or the centrifuge polarizing microscope (CPM). ${ }^{127}$ Of those, a NIZEMI model has already been used in a spacelab mission. Whereas in the first two concepts the optics revolve together with the sample on a centrifuge, the CPM visualizes the rotating sample with an external microscope setup by stroboscopic illumination, precisely synchronized with the centrifuge rotor frequency. Although these microscopes enable gravity-related research, they offer limited imaging modalities (only brightfield and phase contrast) and still have a fairly large spatial footprint. A smaller, advanced SIM fluorescence microscope, dedicated to evaluating DNA damage response in living cells, was recently proposed, but it has not yet been built (Autonomous Microscope for Examination of Radiation Effects (AMERE)). ${ }^{50}$

The trade-off between versatility and compactness has sparked a vivid discussion between two ostensibly opposing ideologies. One argues in favor of a distilled version of a multi-purpose high-end microscope (following up on LMM or AMME), and the other suggests extremely small microscopes for highly specific biological applications (in line with NIZEMI or AMERE but much smaller). This latter concept, which has been brought forward during a meeting of the ESA Topical Team on Advanced Microscopy, was coined "microscope farm" and allows for multiplexing experiments in their entirety, thereby gathering the essential statistical relevance that typically lacks in some of the current space experiments. Proof-of-principle has already been provided through multiple custom-built setups devised to measure calcium fluctuations in osteoblasts and osteosarcoma cells during parabolic and sub-orbital flights. ${ }^{128,129}$ What unites these systems is their simplicity and compact nature. They rely on LED illumination and intensified solid-state (charge injection device) cameras. The use of many microscopes also means that if one breaks down, it will not compromise the entire mission or experiment. Fueled by the rapid evolutions in the fields of photonic miniaturization (e.g., optical waveguides, gradient index lenses, and lens-less microscopy ${ }^{130,131}$ ) and soft lithography, such mini-microscopes could become an affordable disposable. Despite clear advantages with regard to simplicity and statistics, such systems have to be tailored towards specific biological endpoints and, at this stage, they are not likely to provide the desired image quality (signal noise ratio and resolution for similar field of view), nor will they cater for more complex, interactive imaging schemes. Moreover, the space environment, microgravity in particular, will act not only at the cellular level but also on the cellular micro-environment (extracellular matrix and intercellular interactions) and multicellular systems. This calls for a system that can capture and follow cells in more complex samples (spheroids, organoids, and small organisms) for prolonged periods of time. When it comes down to phototoxicity and three-dimensional imaging performance, especially in thicker specimens, LSFM clearly outperforms CFM. We therefore propose a DSLM concept ${ }^{65}$ as a baseline for the next-generation space microscope (Fig. 3). The line scanning approach to FLSM has the additional advantage of spatially uniform illumination, a prerequisite for quantitative imaging. Taking advantage of the high quantum yield of CCD cameras, DSLM allows fast scanning at typical rates of 64 Mpixels/s. Relying on the same optical components as a confocal microscope to scan the light sheet, the optical quality is high with signal to noise ratios of 1000 at maximum imaging speed. ${ }^{65}$ The capability to rotate the sample and to implement structured illumination patterns by digitally modulating the scanning beam allows boosting the image quality even more and removes scatter and background artifacts in non-transparent specimens. ${ }^{70}$ With just one or two 
flip-mirrors and an additional detector, the DSLM can be turned into a CFM (Fig. 3(c)), allowing typical molecular level applications such as FRAP and FLIM. The model depicted in Fig. 3(a) has a minimal spatial footprint (the dimensions of the complete system are $300 \mathrm{~mm}$ by $300 \mathrm{~mm}$ by 250 $\mathrm{mm}$ ), because all opto-mechanical elements are mounted on two sides of an aluminum base plate (illumination side and acquisition side). This makes it possible to use the microscope inside relevant space (e.g., ESA Biolab facility) or groundbased (e.g., LDC) experimental units. Instead of multiplexing mini-scopes to obtain sufficient statistics (microscope farm concept), multiplexing can be performed at the level of the sample and life support system, plausibly in the form of microfluidic chips. With the advent of soft lithography and microfluidics technology, various miniaturized systems have been devised for long-term cultivation of both adherent and suspension cells, either in batch or in the format of a cellular micro-array. ${ }^{132,133}$ Parallelization and miniaturization of cell-based assays is now common practice in two dimensions but is also becoming more feasible in 3D. Indeed, microspace plates have been used to establish three-dimensional cultures of primary hepatocytes, ${ }^{134}$ agarose-coated 384-well plates have been used to perform high-throughput compound screens on spheroids from primary colon cancer cells, ${ }^{135}$ and even a perfusion-based microfluidic chip has been conceived for parallelized 3D culture of primary chondrocytes. ${ }^{136} \mathrm{Com}-$ patibility with LSFM will require alternative well plate geometries as well as a convenient interface for rapid exchange of samples. Previously, we have proposed a robotic arm on a translational stage for exchanging and mounting samples onto an inverted microscope. ${ }^{50}$ Although the sample accommodation might be challenging for an in-flight LSFM, a similar strategy could be considered. Finally, to ensure properly controlled experiments at least one, but preferentially two duplicate microscopes should be built; one for simultaneous recordings within a flight centrifuge and another for parallel Earth-bound experiments. Hence, fabrication cost should be kept as low as possible.

\section{CONCLUSION}

Considering long-term space missions, a clear view on the potential hazards for astronauts is essential. This requires a thorough understanding of the fundamental mechanisms through which microgravity and ionizing radiation affect cellular processes, not only in man but also in plants and other organisms. Ideally, this is done within the relevant environment and in the physiologically most representative conditions. Due to its photo-efficiency, a light sheet-based fluorescence microscope (DSLM) provides an attractive setup for space applications, in particular for developmental biology, plant biology, and mammalian multicellular microenvironments. Moreover, a modular build assures compatibility with a variety of subcellular and molecular level assays while its modest dimensions guarantee compatibility with space and ground-based research facilities. Despite the ostensible opposition between such a high-end microscope and an alternative concept of simplified disposable microscopes, it is conceiv- able that in the future, due to the rapid evolutions in photonics and micro-fabrication technologies, the two concepts will merge. ${ }^{137}$

\section{ACKNOWLEDGMENTS}

The financial support of the Hercules Foundation (AUGE/013) and the European Space Agency support for both the GCCS project and Topical Team on Advanced Compound Microscopy are gratefully acknowledged.

${ }^{1}$ R. Setlow, EMBO Rep. 4, 1013 (2003).

${ }^{2}$ F. A. Cucinotta, F. K. Manuel, J. Jones, G. Iszard, J. Murrey, B. Djojonegro, and M. Wear, Radiat. Res. 156, 460 (2001).

${ }^{3}$ M. Durante and F. A. Cucinotta, Nat. Rev. Cancer 8, 465 (2008).

${ }^{4}$ M. Maalouf, M. Durante, and N. Foray, J. Radiat. Res. 52, 126 (2011).

${ }^{5}$ B. Dieriks, W. De Vos, G. Meesen, K. Van Oostveldt, T. De Meyer, M. Ghardi, S. Baatout, and P. Van Oostveldt, Radiat. Res. 172, 423 (2009).

${ }^{6}$ R. W. BULLARD, Annu. Rev. Physiol. 34, 205 (1972).

${ }^{7}$ J. Grosse, M. Wehland, J. Pietsch, H. Schulz, K. Saar, N. Hübner, C. Eilles, J. Bauer, K. Abou-El-Ardat, S. Baatout, X. Ma, M. Infanger, R. Hemmersbach, and D. Grimm, FASEB J. 26, 5124 (2012).

${ }^{8}$ J. Pietsch, X. Ma, M. Wehland, G. Aleshcheva, A. Schwarzwälder, J. Segerer, M. Birlem, A. Horn, J. Bauer, M. Infanger, and D. Grimm, Biomaterials 34, 7694 (2013).

${ }^{9}$ M. L. Lewis, L. A. Cubano, B. Zhao, H. K. Dinh, J. G. Pabalan, E. H. Piepmeier, and P. D. Bowman, FASEB J. 15, 1783 (2001).

${ }^{10}$ M. L. Beck, M. Moreels, R. Quintens, K. Abou-El-Ardat, H. El-Saghire, K. Tabury, A. Michaux, A. Janssen, M. Neefs, P. Van Oostveldt, W. De Vos, and S. Baatout, Int. J. Mol. Med. 34, 606 (2014).

${ }^{11}$ M. Beck, C. Rombouts, M. Moreels, A. Aerts, R. Quintens, K. Tabury, A. Michaux, A. Janssen, M. Neefs, E. Ernst, B. Dieriks, R. Lee, W. H. De Vos, C. Lambert, P. Van Oostveldt, and S. Baatout, Int. J. Mol. Med. 34, 1124 (2014)

${ }^{12}$ J. L. Becker and G. R. Souza, Nat. Rev. Cancer 13, 315 (2013).

${ }^{13}$ T. E. Johnson and G. A. Nelson, Exp. Gerontol. 26, 299 (1991).

${ }^{14}$ Y. Honda, A. Higashibata, Y. Matsunaga, Y. Yonezawa, T. Kawano, A. Higashitani, K. Kuriyama, T. Shimazu, M. Tanaka, N. J. Szewczyk, N. Ishioka, and S. Honda, Sci. Rep. 2, 487 (2012).

${ }^{15}$ K. Dooley and L. I. Zon, Curr. Opin. Genet. Dev. 10, 252 (2000).

${ }^{16}$ J. Wittbrodt, A. Shima, and M. Schartl, Nat. Rev. Genet. 3, 53 (2002).

${ }^{17}$ M. Masukawa, T. Ochiai, S. Kamigaichi, N. Ishioka, S. Uchida, Y. Kono, and T. Sakimura, Adv. Space Res. 32, 1541 (2003).

${ }^{18}$ T. Sakimura, T. Suzuki, S. Matsubara, S. Uchida, M. Kato, R. Tanemura, and S. Honda, Biol. Sci. Space 13, 314 (1999).

${ }^{19}$ A. I. Manzano, R. Herranz, J. J. W. A. van Loon, and F. Javier Medina, Microgravity Sci. Technol. 24, 373 (2012).

${ }^{20}$ A. L. Paul, M. P. Popp, W. B. Gurley, C. Guy, K. L. Norwood, and R. J. Ferl, Adv. Space Res. 36, 1175 (2005).

${ }^{21}$ A.-L. Paul, R. M. Wheeler, H. G. Levine, and R. J. Ferl, Am. J. Bot. 100, 226 (2013).

${ }^{22}$ F. Gòdia, J. Albiol, J. Pérez, N. Creus, F. Cabello, A. Montràs, A. Masot, and C. Lasseur, Adv. Space Res. 34, 1483 (2004).

${ }^{23}$ G. Clément and K. Slenzka, Fundamentals of Space Biology (Springer, 2006).

${ }^{24}$ G. Horneck, D. M. Klaus, and R. L. Mancinelli, Microbiol. Mol. Biol. Rev. 74, 121 (2010).

${ }^{25}$ K. Johanson, P. L. Allen, R. A. Gonzalez-Villalobos, J. Nesbit, C. A. Nickerson, K. Höner zu Bentrup, J. W. Wilson, R. Ramamurthy, R. D’Elia, K. E. Muse, J. Hammond, J. Freeman, L. S. Stodieck, and T. G. Hammond, Acta Astronaut. 60, 460 (2007).

${ }^{26}$ J. W. Wilson, C. M. Ott, K. Höner zu Bentrup, R. Ramamurthy, L. Quick, S. Porwollik, P. Cheng, M. McClelland, G. Tsaprailis, T. Radabaugh, A. Hunt, D. Fernandez, E. Richter, M. Shah, M. Kilcoyne, L. Joshi, M. Nelman-Gonzalez, S. Hing, M. Parra, P. Dumars, K. Norwood, R. Bober, J. Devich, A. Ruggles, C. Goulart, M. Rupert, L. Stodieck, P. Stafford, L. Catella, M. J. Schurr, K. Buchanan, L. Morici, J. McCracken, P. Allen, C. Baker-Coleman, T. Hammond, J. Vogel, R. Nelson, D. L. Pierson, H. M. Stefanyshyn-Piper, and C. A. Nickerson, Proc. Natl. Acad. Sci. U.S.A. 104, 16299 (2007) 
${ }^{27}$ F. P. Baqai, D. S. Gridley, J. M. Slater, X. Luo-Owen, L. S. Stodieck, V. Ferguson, S. K. Chapes, and M. J. Pecaut, J. Appl. Physiol. 106, 1935 (2009).

${ }^{28}$ T. G. Hammond, E. Benes, K. C. O'Reilly, D. A. Wolf, R. M. Linnehan, A. Taher, J. H. Kaysen, P. L. Allen, and T. J. Goodwin, Physiol. Genomics 3, 163 (2000).

${ }^{29}$ M. Lewis, J. Reynolds, L. Cubano, J. Hatton, B. Lawless, and E. Piepmeier, FASEB J. 12, 1007 (1998).

${ }^{30}$ E. Brinckmann, Biology in Space and Life on Earth (John Wiley \& Sons, 2008).

${ }^{31}$ B. Dieriks, W. H. De Vos, M. Moreels, M. Ghardi, R. Hennekam, J. L. V. Broers, S. Baatout, and P. Van Oostveldt, Mol. Med. Rep. 4, 17 (2011).

${ }^{32}$ F. Pampaloni, E. G. Reynaud, and E. H. K. Stelzer, Nat. Rev. Mol. Cell Biol. 8, 839 (2007).

${ }^{33}$ W. Kim, F. K. Tengra, Z. Young, J. Shong, N. Marchand, H. K. Chan, R. C. Pangule, M. Parra, J. S. Dordick, J. L. Plawsky, and C. H. Collins, PLoS One 8, e62437 (2013).

${ }^{34}$ L. G. Griffith and M. A. Swartz, Nat. Rev. Mol. Cell Biol. 7, 211 (2006).

${ }^{35}$ M. B. Sowa, W. B. Chrisler, K. D. Zens, E. J. Ashjian, and L. K. Opresko, Mutat. Res. 687, 78 (2010).

${ }^{36}$ H. Page, P. Flood, and E. G. Reynaud, Cell Tissue Res. 352, 123 (2012).

${ }^{37}$ F. Pampaloni, N. Ansari, and E. H. K. Stelzer, Cell Tissue Res. 352, 161 (2013).

${ }^{38}$ D. Grimm, M. Wehland, J. Pietsch, G. Aleshcheva, P. Wise, J. van Loon, C. Ulbrich, N. E. Magnusson, M. Infanger, and J. Bauer, "Growing Tissues in Real and Simulated Microgravity: New Methods for Tissue Engineering," Tissue Eng., Part B (published online 2014).

${ }^{39}$ D. Loessner, K. S. Stok, M. P. Lutolf, D. W. Hutmacher, J. A. Clements, and S. C. Rizzi, Biomaterials 31, 8494 (2010).

${ }^{40}$ J. E. Frith, B. Thomson, and P. G. Genever, Tissue Eng. C 16, 735 (2010).

${ }^{41}$ P. Bon, G. Maucort, B. Wattellier, and S. Monneret, Opt. Express 17, 13080 (2009).

${ }^{42}$ V. V. Roshchina, Int. J. Spectrosc. 2012, 124672 (2012).

${ }^{43}$ K. P. Quinn, G. V. Sridharan, R. S. Hayden, D. L. Kaplan, K. Lee, and I. Georgakoudi, Sci. Rep. 3, 3432 (2013).

${ }^{44}$ K. R. Brizzee, J. M. Ordy, and B. Kaack, J. Gerontol. 29, 366 (1974).

${ }^{45}$ M. Chalfie, Y. Tu, G. Euskirchen, W. W. Ward, and D. C. Prasher, Science 263, 802 (1994).

${ }^{46}$ N. Shaner, P. Steinbach, and R. Tsien, Nat. Methods 2, 905 (2005).

${ }^{47}$ W.-G. W. Choi, S. J. S. Swanson, and S. S. Gilroy, Plant J. 70, 118 (2012).

${ }^{48}$ C. Baumstark-Khan, C. Hellweg, M. Palm, and G. Horneck, Phys. Med. 17, 210-214 (2001).

${ }^{49}$ C. Baumstark-Khan, C. E. Hellweg, A. Arenz, and M. M. Meier, Radiat. Res. 164, 527 (2005)

${ }^{50}$ W. H. De Vos, G. Meesen, C. Szpirer, S. Scohy, C. Cherukuri, O. Evrard, X. Hutsebaut, and D. Beghuin, Planet. Space Sci. 74, 84 (2012).

${ }^{51}$ B. Jakob, J. Splinter, M. Durante, and G. Taucher-Scholz, Proc. Natl. Acad. Sci. U.S.A. 106, 3172 (2009).

${ }^{52}$ P. Back, W. H. De Vos, G. G. Depuydt, F. Matthijssens, J. R. Vanfleteren, and B. P. Braeckman, Free Radical Biol. Med. 52, 850 (2012).

${ }^{53}$ N. Van Bruaene, G. Joss, and P. Van Oostveldt, Plant Physiol. 136, 3905 (2004).

${ }^{54}$ A. Maizel, D. von Wangenheim, F. Federici, J. Haseloff, and E. H. K. Stelzer, Plant J. 68, 377 (2011).

${ }^{55}$ P. Sarder and A. Nehorai, IEEE Signal. Process. Mag. 23, 32 (2006).

${ }^{56}$ J.-A. Conchello and J. W. Lichtman, Nat. Methods 2, 920 (2005).

${ }^{57} \mathrm{P}$. Křížek and G. M. Hagen, in Current Microscopy Contributions to Advances in Science and Technology, edited by A. Mendez-Vilas (Formatex, 2012).

${ }^{58}$ D. Kobat, N. G. Horton, and C. Xu, J. Biomed. Opt. 16, 106014 (2011).

${ }^{59}$ N. G. Horton, K. Wang, D. Kobat, C. G. Clark, F. W. Wise, C. B. Schaffer, and C. Xu, Nat. Photonics 7, 205 (2013).

${ }^{60}$ F. Helmchen and W. Denk, Nat. Methods 2, $932(2005)$.

${ }^{61}$ J. Huisken and D. Y. R. Stainier, Development 136, 1963 (2009).

${ }^{62}$ P. A. Santi, J. Histochem. Cytochem. 59, 129 (2011).

${ }^{63}$ J. Huisken, J. Swoger, F. Del Bene, J. Wittbrodt, and E. H. K. Stelzer, Science 305, 1007 (2004).

${ }^{64}$ P. J. Keller, A. D. Schmidt, J. Wittbrodt, and E. H. K. Stelzer, Science 322, 1065 (2008).

${ }^{65}$ P. J. Keller and E. H. K. Stelzer, Curr. Opin. Neurobiol. 18, 624 (2008).

${ }^{66}$ U. Krzic, S. Gunther, T. E. Saunders, S. J. Streichan, and L. Hufnagel, Nat. Methods 9, 730 (2012).

${ }^{67}$ F. Strobl and E. H. K. Stelzer, Development 141, 2331 (2014).
${ }^{68}$ H.-U. Dodt, U. Leischner, A. Schierloh, N. Jährling, C. P. Mauch, K. Deininger, J. M. Deussing, M. Eder, W. Zieglgänsberger, and K. Becker, Nat. Methods 4, 331 (2007).

${ }^{69}$ J. Huisken and D. Y. R. Stainier, Opt. Lett. 32, 2608 (2007).

${ }^{70}$ P. J. Keller, A. D. Schmidt, A. Santella, K. Khairy, Z. Bao, J. Wittbrodt, and E. H. K. Stelzer, Nat. Methods 7, 637 (2010).

${ }^{71}$ E. Baumgart and U. Kubitscheck, Opt. Express 20, 21805 (2012).

${ }^{72}$ L. Silvestri, A. Bria, L. Sacconi, G. Iannello, and F. S. Pavone, Opt. Express 20, 20582 (2012).

${ }^{73}$ T. V. Truong, W. Supatto, D. S. Koos, J. M. Choi, and S. E. Fraser, Nat. Methods 8, 757 (2011).

${ }^{74}$ F. O. Fahrbach, P. Simon, and A. Rohrbach, Nat. Photonics 4, 780 (2010).

${ }^{75}$ T. A. Planchon, L. Gao, D. E. Milkie, M. W. Davidson, J. A. Galbraith, C. G. Galbraith, and E. Betzig, Nat. Methods 8, 417 (2011).

${ }^{76}$ M. Zhao, H. Zhang, Y. Li, A. Ashok, R. Liang, W. Zhou, and L. Peng, Biomed. Opt. Express 5, 1296 (2014).

${ }^{77}$ S. Abrahamsson, J. Chen, B. Hajj, S. Stallinga, A. Y. Katsov, J. Wisniewski, G. Mizuguchi, P. Soule, F. Mueller, C. Dugast-Darzacq, X. Darzacq, C. Wu, C. I. Bargmann, D. A. Agard, M. Dahan, and M. G. L. Gustafsson, Nat Methods 10, 60 (2013).

${ }^{78}$ R. Tomer, K. Khairy, F. Amat, and P. J. Keller, Nat. Methods 9, 755 (2012).

${ }^{79}$ K. Mohan, S. B. Purnapatra, and P. P. Mondal, PLoS One 9, e96551 (2014).

${ }^{80}$ F. O. Fahrbach, F. F. Voigt, B. Schmid, F. Helmchen, and J. Huisken, Opt. Express 21, 21010 (2013).

${ }^{81}$ G. Donnert, C. Eggeling, and S. W. Hell, Nat. Methods 4, 81 (2007).

${ }^{82}$ R. A. Hoebe, C. H. Van Oven, T. W. J. Gadella, P. B. Dhonukshe, C. J. F. Van Noorden, and E. M. M. Manders, Nat. Biotechnol. 25, 249 (2007).

${ }^{83}$ W. H. De Vos, R. A. Hoebe, G. H. Joss, W. Haffmans, S. Baatout, P. Van Oostveldt, and E. M. M. Manders, Cytometry 75, 428 (2009).

${ }^{84}$ R. Peters, J. Peters, K. H. Tews, and W. Bähr, Biochim. Biophys. Acta 367, 282 (1974).

${ }^{85}$ J. Lippincott-Schwartz, N. Altan-Bonnet, and G. H. Patterson, Nature Cell Biology 5, S7-S14 (2003).

${ }^{86}$ R. Peters, A. Brünger, and K. Schulten, Proc. Natl. Acad. Sci. U.S.A. 78, 962 (1981).

${ }^{87}$ G. A. Dunn, I. M. Dobbie, J. Monypenny, M. R. Holt, and D. Zicha, J. Microsc. 205, 109 (2002).

${ }^{88}$ G. H. Patterson and J. Lippincott-Schwartz, Science 297, 1873 (2002).

${ }^{89}$ M. B. Elowitz, M. G. Surette, P. E. Wolf, J. Stock, and S. Leibler, Curr. Biol. 7, 809 (1997).

${ }^{90}$ R. Ando, H. Hama, M. Yamamoto-Hino, H. Mizuno, and A. Miyawaki, Proc. Natl. Acad. Sci. U.S.A. 99, 12651 (2002).

${ }^{91}$ J. C. Politz, Trends Cell Biol. 9, 284 (1999).

${ }^{92}$ P. I. Bastiaens, I. V. Majoul, P. J. Verveer, H. D. Söling, and T. M. Jovin, EMBO J. 15, 4246 (1996).

${ }^{93}$ E. Kohen, Cell Structure and Function by Microspectrofluorometry (Academic Press, 1989).

${ }^{94}$ T. W. Gadella and T. M. Jovin, J. Cell Biol. 129, 1543 (1995).

${ }^{95}$ P. I. P. Bastiaens and A. A. Squire, Trends Cell Biol. 9, 48 (1999).

${ }^{96}$ T. Förster, J. Biomed. Opt. 17, 011002 (2012).

${ }^{97}$ T. Förster, Ann. Phys. 437, 55 (1948).

${ }^{98}$ D. M. Chudakov, M. V. Matz, S. Lukyanov, and K. A. Lukyanov, Physiol. Rev. 90, 1103 (2010).

${ }^{99}$ E. A. Jares-Erijman and T. M. Jovin, Nat. Biotechnol. 21, 1387 (2003).

${ }^{100}$ M. Elangovan, R. N. Day, and A. Periasamy, J. Microsc. 205, 3 (2002).

${ }^{101}$ R. A. Bhat, T. Lahaye, and R. Panstruga, Plant Methods 2, 12 (2006).

${ }^{102}$ A. Delporte, W. H. De Vos, and E. J. M. Van Damme, J. Plant Physiol. 171, 1149 (2014)

${ }^{103}$ E. Betzig, G. H. Patterson, R. Sougrat, O. W. Lindwasser, S. Olenych, J. S. Bonifacino, M. W. Davidson, J. Lippincott-Schwartz, and H. F. Hess, Science 313, 1642 (2006).

${ }^{104}$ M. J. Rust, M. Bates, and X. Zhuang, Nat. Methods 3, 793 (2006).

${ }^{105}$ S. W. Hell and M. Kroug, Appl. Phys. B 60, 495 (1995).

${ }^{106}$ S. Hell and E. Stelzer, Opt. Commun. 93, 277 (1992).

${ }^{107}$ S. W. Hell and J. Wichmann, Opt. Lett. 19, 780 (1994).

${ }^{108}$ B. Huang, M. Bates, and X. Zhuang, Annu. Rev. Biochem. 78, 993 (2009).

${ }^{109}$ L. Schermelleh, R. Heintzmann, and H. Leonhardt, J. Cell Biol. 190, 165 (2010).

${ }^{110}$ I. Izeddin, C. G. Specht, M. Lelek, X. Darzacq, A. Triller, C. Zimmer, and M. Dahan, PLoS One 6, e15611 (2011).

${ }^{111}$ U. V. Nägerl, K. I. Willig, B. Hein, S. W. Hell, and T. Bonhoeffer, Proc. Natl. Acad. Sci. U.S.A. 105, 18982 (2008). 
${ }^{112}$ F. F. C. Zanacchi, Z. Z. Lavagnino, M. M. P. Donnorso, A. A. Del Bue, L. L. Furia, M. M. Faretta, and A. A. Diaspro, Nat. Methods 8, 1047 (2011).

${ }^{113}$ F. C. Zanacchi, Z. Lavagnino, M. Faretta, L. Furia, and A. Diaspro, PLoS One 8, e67667 (2013).

${ }^{114}$ M. Friedrich, Q. Gan, V. Ermolayev, and G. S. Harms, Biophys. J. 100, L43 (2011).

${ }^{115}$ M. G. Gustafsson, J. Microsc. 198, 82 (2000).

${ }^{116}$ M. A. Neil, R. Juskaitis, and T. Wilson, Opt. Lett. 22, 1905 (1997).

${ }^{117}$ C. T. Lant and A. Resnick, AIP Conf. Proc. 504, 324 (2000).

${ }^{118}$ N. Ishioka, H. Suzuki, M. Asashima, S. Kamisaka, Y. Mogami, T. Ochiai, S. Aizawa-Yano, A. Higashibata, N. Ando, M. Nagase, S. Ogawa, T. Shimazu, K. Fukui, and N. Fujimoto, J. Gravit. Physiol. 11, 81 (2004).

${ }^{119}$ D. Beghuin, M. Ameloot, and D. Claessens, Proc. SPIE 5858, 585808 (2005).

${ }^{120}$ M. Durante, G. Reitz, and O. Angerer, Radiat. Environ. Biophys. 49, 295 (2010).

${ }^{121}$ P. Baert, T. Van Cleynenbreugel, J. Vandesompele, S. De Schynkel, J. Vander Sloten, and P. Van Oostveldt, Acta Astronaut. 58, 456 (2006).

${ }^{122}$ J. van Loon, Adv. Space Res. 39, 1161 (2007).

${ }^{123}$ J. Van Loon, J. Krause, H. Cunha, J. Goncalves, H. Almeida, and P. Schiller, Proceedings of the Life in Space for Life on Earth Symposium (ESA, 2008), p. 22.

${ }^{124}$ J. Van Loon, J. Gravit. Physiol. 11, 57 (2004).

${ }^{125}$ U. Friedrich, O. Joop, C. Putz, and G. Willich, J. Biotechnol. 47, 225 (1996).
${ }^{126}$ R. Braucker and H. Machemer, Microgravity Sci. Technol. 13, 3 (2002).

${ }^{127}$ S. Inoué, R. A. Knudson, M. Goda, K. Suzuki, C. Nagano, N. Okada, H. Takahashi, K. Ichie, M. Iida, and K. Yamanaka, J. Microsc. 201, 341 (2001).

${ }^{128}$ D. B. Jones, Proc. Royal Microsc. Soc. 38, 67 (2003).

${ }^{129}$ J. Struckmeier, E. Klopp, M. Born, M. Hofmann, J. Tenbosch, and D. B. Jones, Rev. Sci. Instrum. 71, 4531 (2000).

${ }^{130}$ O. Mudanyali, D. Tseng, C. Oh, S. O. Isikman, I. Sencan, W. Bishara, C. Oztoprak, S. Seo, B. Khademhosseini, and A. Ozcan, Lab Chip 10, 1417 (2010).

${ }^{131}$ T. A. Murray and M. J. Levene, J. Biomed. Opt. 17, 021106 (2012).

${ }^{132}$ K. R. King, S. Wang, D. Irimia, A. Jayaraman, M. Toner, and M. L. Yarmush, Lab Chip 7, 77 (2007).

${ }^{133}$ S. K. Moore and S. J. Kleis, Acta Astronaut. 62, 632 (2008).

${ }^{134}$ M. Nishimura, M. Hagi, Y. Ejiri, S. Kishimoto, T. Horie, S. Narimatsu, and S. Naito, Drug Metab. Pharmacokinet. 25, 236 (2010).

${ }^{135}$ C. Wenzel, B. Riefke, S. Gründemann, A. Krebs, S. Christian, F. Prinz, M. Osterland, S. Golfier, S. Räse, N. Ansari, M. Esner, M. Bickle, F. Pampaloni, C. Mattheyer, E. H. Stelzer, K. Parczyk, S. Prechtl, and P. Steigemann, Exp. Cell Res. 323, 131 (2014).

${ }^{136}$ S. B. Huang, M. H. Wu, S. S. Wang, and G.-B. Lee, Biomed. Microdevices 13, 415 (2011)

${ }^{137}$ C. J. Engelbrecht, F. Voigt, and F. Helmchen, Opt. Lett. 35, 1413 (2010). 